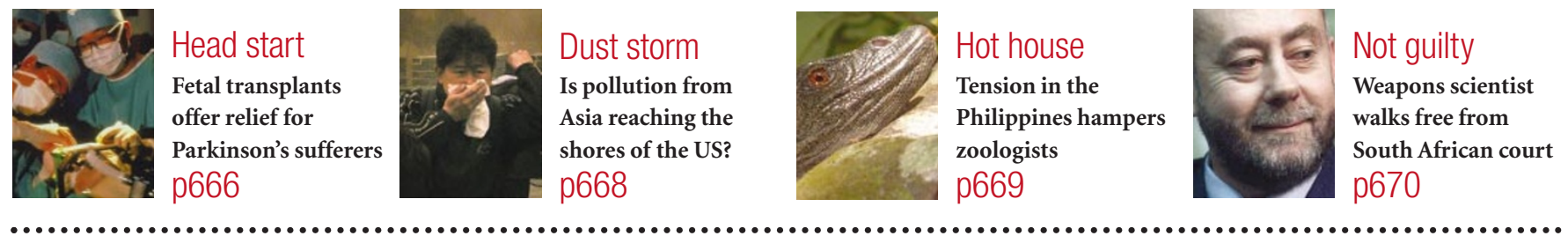

\title{
Frogs put in the gender blender by America's favourite herbicide
}

\section{Rex Dalton, Berkeley}

Low levels of the most widely used herbicide in the United States have been found to disrupt the sexual development of frogs. The finding will heighten concerns about the persistence of endocrine-disrupting chemicals in the environment — and throws the spotlight on another potential factor involved in the global decline of amphibian populations.

In the United States, about 27,000 tonnes of atrazine are applied each year to fields used to grow crops such as maize, sorghum and sugar cane. It is also used in 80 other nations, making it one of the world's most important herbicides. But concerns about atrazine's potential ability to disrupt sex hormones, and the presence of residues in drinking water, have led it to be banned in Germany, France, Italy, Sweden, Norway and Switzerland.

Tyrone Hayes and his colleagues at the University of California, Berkeley, exposed tadpoles of the African clawed frog (Xenopus laevis) to water containing different levels of atrazine throughout their larval development. Levels as low as 0.1 parts per billion (p.p.b.) caused males to develop ovaries in addition to testes. And at concentrations above 1 p.p.b., male frogs' larynges — used to call for mates - failed to develop normally, Hayes reports in a paper published on 16 April (T. B. Hayes et al. Proc. Natl Acad. Sci. USA 99, 5476-5480; 2002).

In addition, when the researchers put adult males in water containing 25 p.p.b. of atrazine, their testosterone levels plummeted. And in preliminary, unpublished research, Hayes has found similar reproductive anomalies in wild leopard frogs (Rana pipiens) at six locations in the midwestern United States with high levels of atrazine.

"It is obviously affecting frogs," says Hayes, who suspects that atrazine boosts production of the enzyme aromatase, which catalyses the conversion of testosterone into oestrogen. "We need to ask: what are the environmental costs of using atrazine?" he says.

Although previous studies have suggested that atrazine is an endocrine disrupter, these have mostly used much higher doses. Hayes's study is causing alarm because he has

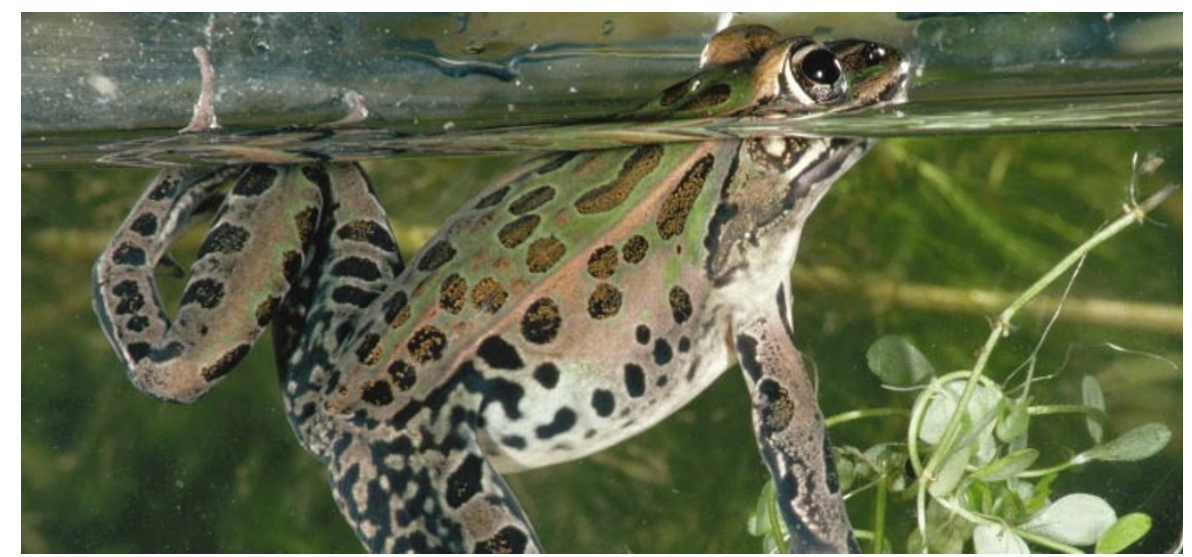

Do environmental levels of atrazine cause sexual defects in leopard frogs in the US midwest?

observed effects at concentrations that reflect those found in the environment. "Hayes's work is some of the best to show how a contaminant affects amphibian reproduction," says Andrew Blaustein, who studies amphibians at Oregon State University in Corvallis.
"This is not a worst-case scenario where animals are exposed to mega-doses," says Louis Guillette, a zoologist at the University of Florida in Gainesville. "These are concentrations we know wild amphibians are exposed to." Indeed, atrazine is routinely found at

\section{Scripps to trawl sea-microbe data}

Jonathan Knight, San Francisco

The genomic secrets of the ocean's microbes are set to be revealed by the world's first centre devoted to marine bioinformatics. The Scripps Institution of Oceanography in La Jolla, California, plans to establish the facility within the next few months.

The centre's main focus will be microbial genomics, says Ron Burton, director of marine biology at Scripps. Most of the marine genomes sequenced so far have been microorganisms - yet their biochemistry and ecology remains poorly understood, despite their crucial role in the global cycling of carbon and nitrogen (see Nature 415, 572-574; 2002).

The Scripps centre will not itself sequence marine genomes, Burton says. That work will continue at places such as the Joint Genome Institute in Walnut Creek, California, where a number of marine microbes have so far been sequenced. Rather, the new facility's emphasis will be on teasing information about ocean life from the sequence databases.

For example, Brian Palenik's laboratory at Scripps has already started to apply bioinformatics techniques to learn how microbes relate to their ocean environment. Traditionally, biologists have probed this question by studying microorganisms in laboratory flasks. But genomics can help to reveal the factors that contribute to a microbe's survival. Palenik has discovered several overlooked metabolic pathways in cyanobacteria, photosynthetic microbes that are responsible for $80 \%$ of the carbon fixed from the atmosphere in the open ocean.

The new division will eventually consist of about 10 faculty members, and will cost upwards of \$20 million to establish. A director has yet to be appointed, but the leading candidate is said to be a well-known figure in the bioinformatics field. 
50 p.p.b. in water throughout the United States, experts say, and can rise to several parts per million in agricultural run-off.

Amphibians are highly sensitive to pollutants and are regarded as 'sentinel' species that can provide the first indications of damage to an ecosystem. Hayes's results come as the US Environmental Protection Agency (EPA) is re-evaluating the risks posed by atrazine - following a 1999 ruling on a lawsuit from the Natural Resources Defense Council and other environmental groups, requiring the agency to accelerate its efforts to reassess the environmental and health risks posed by a range of potential

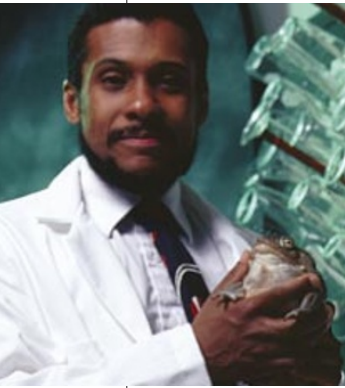
endocrine disrupters.

The EPA currently allows levels of atrazine to reach 3 p.p.b.in US drinking water. An EPA panel will hold a public meeting this week in Arlington, Virginia, on suggested residue levels of atrazine in food products.

Hayes has provided Tyrone Hayes has the EPA with a report on fears for frogs. his unpublished fieldwork on frogs from

Colorado to Wisconsin, but EPA officials declined to comment on this, or on Hayes's newly published paper. The agency aims to issue final reports on the risks posed by atrazine by August.

Atrazine is manufactured by Syngenta of Basel, Switzerland. Alan Hosmer, Syngenta's manager of ecological sciences in Greensboro, North Carolina, says that the firm is aware of some of Hayes's results. But the company failed to provide a detailed statement before Nature went to press. For three years, Hayes worked on contract research at Berkeley for Syngenta. But he severed relations with the firm last year, independently pursuing the studies that led to this week's paper.

Aside from their implications for the use of atrazine in the United States and elsewhere, Hayes's results add another element to the debate over why amphibian populations are declining across the world. Many factors are thought to be involved, including pathogens, pollution, competition with invading alien species, and habitat loss.

James Hanken, a herpetologist at Harvard University who chairs the international Declining Amphibian Populations Task Force, describes Hayes's results as "compelling". But he notes that some of the most severe declines are in Central America, where atrazine is not thought to be widely used. Hanken argues that further studies are needed to determine what role atrazine and related chemicals are playing in amphibian declines across the globe.

www.open.ac.uk/daptt

\section{Parkinson's patients show positive response to implants}

\section{Erika Check, Washington}

Fetal cells transplanted into the brains of patients with Parkinson's disease can survive and mature for up to eight years after the surgery, helping to alleviate the debilitating tremors seen in the disease. These positive results, from a trial that last year attracted controversy because of the side-effects experienced by a small number of patients, should help to lift the cloud that has since hung over cellular therapies for the condition.

Parkinson's is caused by the death of cells that secrete the neurotransmitter dopamine. When Curt Freed of the University of Colorado and his colleagues reported on the trial last year, their results confirmed that transplanted cells from the brains of aborted fetuses can help to relieve the symptoms of the disease (see Nature 410, 401; 2001). But five of the 20 patients treated experienced jerky, uncontrolled movements called dyskinesias.

This week, at a meeting of the American Academy of Neurology in Denver, Colorado, Freed reported that these patients have since responded to treatment aimed at addressing this unwanted side-effect either by giving them drugs to remove excess dopamine or by implanting a device called a 'deep-brain stimulator', which delivers timed electric shocks to the brain region that causes the dyskinesias. Indeed, one of the dyskinetic patients was working in the World Trade Center at the time of the 11 September attacks last year, and was able to make his escape by walking down 33 flights of stairs.

The new results are from a total of 32 patients. The trial was expanded by relaxing its double-blind design and allowing some patients who had initially been in the control group to have the transplants. The degree of improvement varied between patients, but seemed to be independent of age - the team's earlier data had suggested that only those younger than 60 benefited. Patients who did best were those who had previously responded most strongly to the drug L-DOPA, which is converted to dopamine in the brain.

Autopsies on three patients who died up to eight years after surgery showed that the transplanted fetal cells were making increasing amounts of a pigment called neuromelanin. Neurons make neuromelanin as they age. "This says the dopamine neurons we've transplanted appear to be developing as though they were in normal human brain environments," says Freed.

This result is particularly encouraging, says Ole Isacson, a Parkinson's expert at

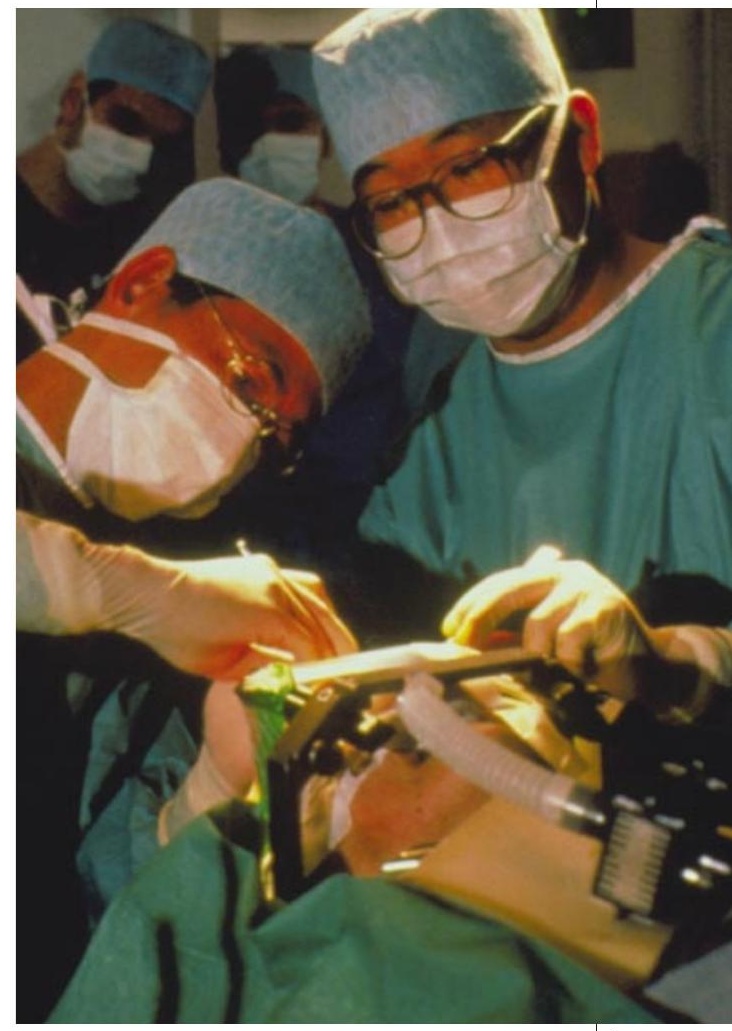

Fetal cells transplanted into the brains of patients with Parkinson's can ease the disease's symptoms.

Harvard Medical School. "Maturation is the key," he says. "These grafts need to grow and mature to become effective."

But Isacson and other researchers say that cellular therapies will need further refinement if they are to deliver better results than conventional drug therapy. They note that Freed's team transplanted cells into a brain structure called the putamen, which contains the cells that respond to dopamine. But Ivar Mendez, a neurosurgeon at Dalhousie University in Halifax, Nova Scotia, has begun a pilot study in which five patients have received fetal-cell transplants into both the putamen and the substantia nigra - the structure that contains the dopaminesecreting cells lost in Parkinson's.

Mendez also treats fetal cells with a biochemical called glial-cell-line-derived neurotrophic factor before transplanting them. A brain-imaging study indicates that these treated cells survive better in their new environment. Mendez's patients also seem to improve faster than those in Freed's trial.

Other groups, meanwhile, are working on techniques to grow dopamine-producing neurons from cultures of human embryonic or adult neural stem cells, which would remove the need to obtain material from freshly aborted fetuses. 